\title{
FREQUENCY OF BSMI POLYMORPHISM OF VITAMIN D RECEPTOR GENE AND ITS ASSOCIATION WITH 25-HYDROXYVITAMIN D LEVELS Mahmut Selman Yıldırım ${ }^{4}$ Aysegül Zamani ${ }^{4}$
}

1-Dr Vefa Tanır Ilgın State Hospital Department of Internal Medicine, 2- Necmettin Erbakan University Meram Faculty of Medicine Department of Endocrinology and Metabolism, 3-Afyonkarahisar State Hospital Department of Internal Medicine, 4- Necmettin Erbakan University Meram Faculty of Medicine Department of Medical Genetics

\section{INTRODUCTION}

Vitamin D deficiency has become a major public health problem. It's known that the effects of vitamin $D$ are made by its receptors. Vitamin D receptor (VDR) is a member of nuclear receptors type 1 such as androgen, estrogen, progesterone and glucocorticoid receptor. In several studies carried out up to 30 different cells and tissues of the vitamin $D$ receptor (VDR) have shown the presence. In many studies ongoing malignancies and their relationship with Vitamin D and VDR are being investigated. VDR gene polymorphisms in susceptibility to different diseases demonstrated in many studies. The polymorphisms of VDR are Apal, Taql, Fokl and Bsml. Bsml is the most extensively studied polymorphism. In a study conducted for osteoporosis BB genotype was reported to be low risk indicator [1].

In our study, the aim is to show the frequency of VDR Bsml gene polymorphisms and to show the relationship between polymorphisms and vitamin D levels.

METHOD

All population were divided into two groups which are 100 osteoporotic and 100 non-osteoporotic. The demographic characteristics were recorded. In blood samples vitamin D, calcium, phosphorus, alkaline phosphatase; in urine samples urinary calcium, urinary creatinine were studied. In addition, approximately $2 \mathrm{cc}$ of peripheral blood sample was taken for DNA isolation and VDR Bsml polymorphisms were studied by real-time PCR method and comparisons were made between the groups.

\section{RESULTS}

In all of population BB genotype $17 \%$, Bb genotype $50.5 \%$ and bb genotype $32.5 \%$ were found. In osteoporotic grup BB genotype $16 \%$, Bb genotype $48 \%$ and bb genotype $36 \%$ were found. In non-osteoporotic grup BB genotype $18 \%, \mathrm{Bb}$ genotype $53 \%$ and bb genotype $29 \%$ were found. There was no statistically significant difference between groups $(p=0.571)$. The level of vitamin D was $18.10 \mathrm{ng} / \mathrm{mL}$ in BB genotype, 17.08 $\mathrm{ng} / \mathrm{mL}$ in $\mathrm{Bb}$ genotype and $16.34 \mathrm{ng} / \mathrm{mL}$ in bb genotype. There was no statistically significant difference between genotypes $(p=0.717)$.

Fig 1: Vitamin D levels in genotypes

\begin{tabular}{|l|l|l|l|l|}
\hline & BB & Bb & bb & p \\
\hline Vitamin D $(\mathrm{ng} / \mathrm{mL})$ & $18.10 \pm 10.77$ & $17.08 \pm 10.25$ & $16.34 \pm 9.59$ & 0.717
\end{tabular}

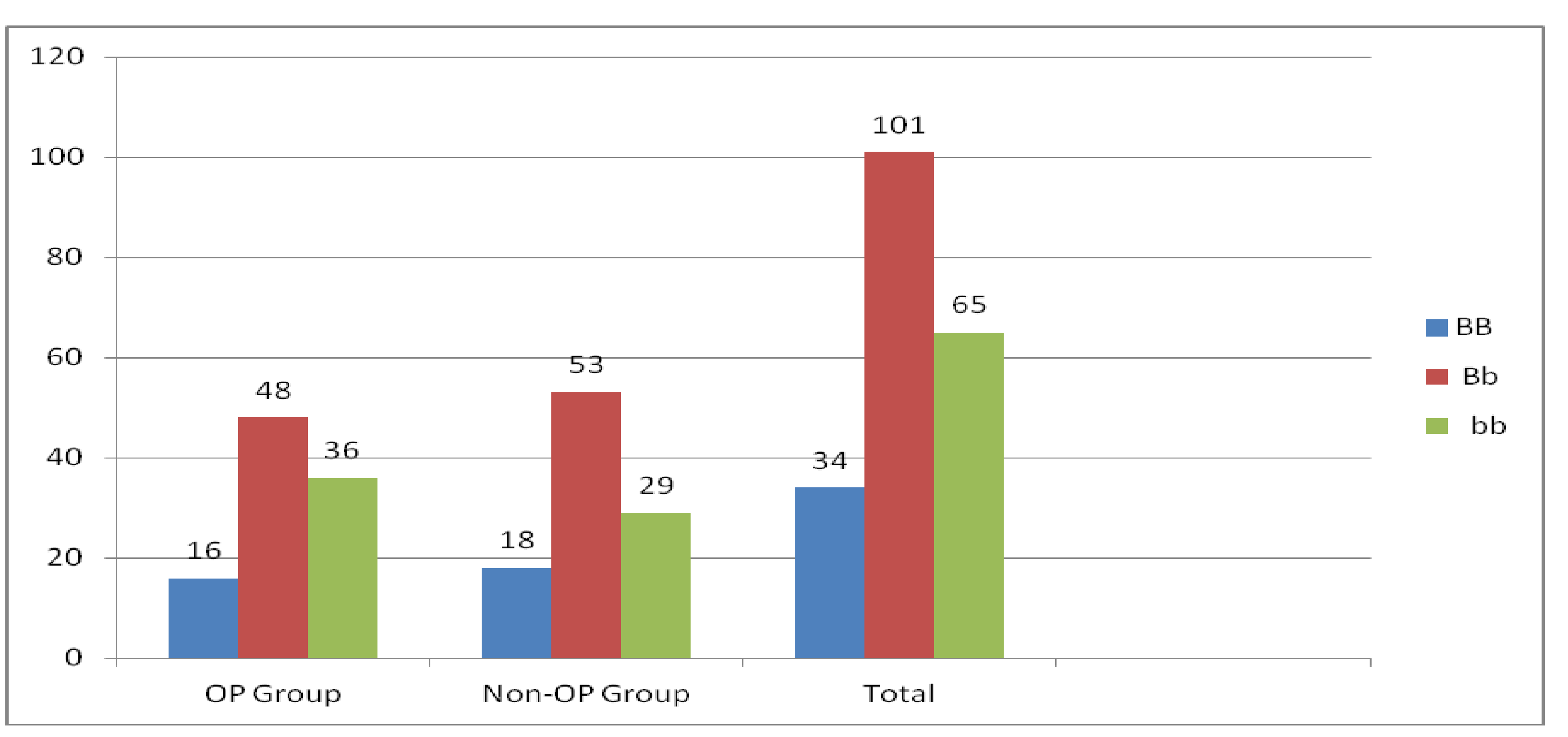

Fig 2: Allels in Groups

DISCUSSION

Has been seen in studies of vitamin D deficiency, especially in developed countries has become a common public health problem [2]. Adequate levels of vitamin $D$ that is currently under discussion but the critical value for the prevention of pathological conditions today minimum qualification as $30 \mathrm{ng} /$ $\mathrm{mL}$ was determined [3]. In the absence of susceptibility to some diseases, there was an increase in morbidity and mortality [4]. VDR and vitamin $D$ levels in studies investigating the relationship made and different results were obtained. In a study conducted in Tunisia in asthmatic children has not been shown that the relationship [5], but In a study on childreen in Japan there was a relationship between VDR and vitamin $D$ deficiency [6]. Examined the relationship between BMD and VDR polymorphisms in the world and in our country, despite the fact that numerous studies conducted have found conflicting results with each other. In a study conducted in Slovenia with femoral neck BMD was found a negative relationship between Bsml polymorphism [7]. On the other hand in a study conducted in the Czech Republic in postmenopausal women with BMD in the relationship between BSM has not been shown [8].

\section{CONCLUSION}

In our study there was no statistically significant relationship between genotypes and vitamin $D$ levels and also was no statistically significant relationship of VDR gene Bsml polymorphisms between two groups. Serious vitamin D deficiency was detected in both groups and the whole population.

REFERENCES:

1. Mckay, J.D.,
and al., Vitamin D receptor polymorphisms and breast cancer risk: results from the National Cancer Institute Breast 2. Holick, M.F., Vitamin D deficiency in 2010: health benefits of vitamin D and sunlight: a D-bate. Nat Rev Endocrinol, 2011. 7(2): p. 3. Holick, M.F. and T.C. Chen, Vitamin D deficiency: a worldwide problem with health consequences. Am I Clin Nutr, 2008. 87(4): p. 4. Melamed, M.L., et al., Serum 25-hydroxyvitamin D levels and the prevalence of peripheral arterial disease: results from NHANES 4. 5. Maalmi, H., et al., The impact of vitamin D deficiency on immune $T$ cells in asthmatic children: a case-control study. J Asthm
Allergy, 2012. 5 : p. $11-9$. 6. Kitanaka, S., et all., Association of vitamin D-related gene polymorphisms with maniffestation of vitamin D deficiency in children.

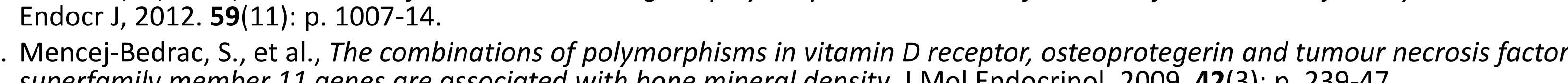

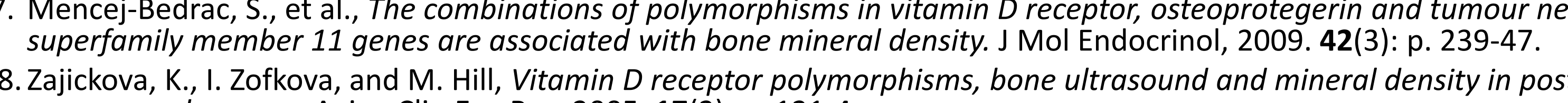

